\title{
PREFERENSI WISATAWAN MILENIAL NUSANTARA PADA DAYA TARIK WISATA SWAFOTO DI BALI
}

\section{MILLENNIAL DOMESTIC TOURIST PREFERENCES IN THE SELFIE TOURIST ATTRACTION IN BALI}

\author{
Putu Devi Rosalina ${ }^{1}$, Luh Eka Susanti ${ }^{2}$, dan Made Widya Paramitha ${ }^{3}$ \\ ${ }^{12}$ Sekolah Tinggi Pariwisata Bali Internasional \\ putudevi@stpbi.ac.id
}

\begin{abstract}
Millennial tourists regards traveling not just about enjoying nature and culture, or strolling around, instead millennials assume that traveling is when immersed in an interesting experience. The purpose of this study is to find out how the preferences of domestik millennial tourists visiting Selfie Tourist Attraction (STA) in Bali are, as well as what tourist activities needed to be developed. The approach in this research is qualitative, referring to McIntosh's Motivation theory and Leiper's Tourist Attraction Theory. The locus of research is in five STAs including: Twin Hill in Gianyar Regency, Big Garden Corner in Denpasar City, Tukad Badung in Denpasar City, Merta Sari Sanur Beach and Selfie Wanagiri Tourism in Buleleng Regency . Data will be collected through interview and the distribution of 50 questionnaires with accidental sampling. The results revealed that the majority of tourists' motivation to visit is driven by the desire to escape or so-called Fantasy Motivation by $50 \%$, while physical motivation is by $26 \%$, social by is $20 \%$, and culture is merely by $4 \%$. Furthermore, regarding its preference analysis, domestic millenial tourists are very supportive for the government's performance and enthusiastic for the success of the stakeholders in developing and advancing STA, as seen from the percentage of $94 \%$ of tourists choosing to visit by considering the success of the stakeholders in managing STA. In addition, there are a number of tourism activities that need to be developed to optimize the potential of STA, such as: holding cultural events on a regular basis, adding playgrounds for children, adding spots for selfies, and renovating selfie photo spots that are already inadequate. Tourists also argued the need to maintain cleanliness and the addition of public facilities.
\end{abstract}

Keywords: Tourist Preferences, Tourist Motivation, Millennial Tourists, Selfie Tourist Attraction

\begin{abstract}
ABSTRAK
Wisatawan Millenial menganggap bepergian bukan hanya tentang menikmati alam dan budaya, atau berjalan-jalan, tetapi milenial beranggapan bahwa bepergian adalah ketika terbenam dalam pengalaman yang menarik. Tujuan dari penelitian ini adalah untuk mengetahui bagaimana preferensi wisatawan domestik milenial yang mengunjungi Selfie Tourist Attraction (STA) di Bali, serta kegiatan wisata apa yang perlu dikembangkan. Pendekatan dalam penelitian ini adalah kualitatif, mengacu pada teori Motivasi McIntosh dan Teori Daya Tarik Wisata Leiper. Lokasi penelitian adalah di lima STA termasuk: Bukit Kembar di Kabupaten Gianyar, Big Garden Corner di Kota Denpasar, Tukad Badung di Kota Denpasar, Pantai Merta Sari Sanur dan Wisata Selfie Wanagiri di Kabupaten
\end{abstract}


Buleleng. Data akan dikumpulkan melalui wawancara dan distribusi 50 kuesioner dengan accidental sampling. Hasil penelitian menunjukkan bahwa sebagian besar motivasi wisatawan untuk berkunjung didorong oleh keinginan untuk melarikan diri atau disebut Fantasi Motivasi sebesar 50\%, sedangkan motivasi fisik sebesar 26\%, sosial sebesar 20\%, dan budaya hanya sebesar $4 \%$. Selanjutnya, mengenai analisis preferensi, wisatawan millenial domestik sangat mendukung kinerja pemerintah dan antusias terhadap keberhasilan para pemangku kepentingan dalam mengembangkan dan memajukan STA, seperti yang terlihat dari persentase $94 \%$ wisatawan yang memilih untuk berkunjung dengan mempertimbangkan keberhasilan pemangku kepentingan dalam mengelola STA. Selain itu, ada sejumlah kegiatan pariwisata yang perlu dikembangkan untuk mengoptimalkan potensi STA, seperti: mengadakan acara budaya secara rutin, menambahkan taman bermain untuk anak-anak, menambahkan tempat untuk selfie, dan merenovasi tempat foto selfie yang sudah tidak memadai. Wisatawan juga berpendapat perlunya menjaga kebersihan dan penambahan fasilitas umum.

Kata kunci: Preferensi Turis, Motivasi Turis, Turis Millenial, Daya Tarik Wisata Selfie

\section{PENDAHULUAN}

Dilihat dari sangat besarnya keaktifan masyarakat Indonesia untuk menggunakan sosial media, maka menjadi peluang besar pula dari segi pariwisata. Bali yang sangat terkenal dengan popularitas destinasi wisatanya, dari segi promosi kini tidak lagi mengandalkan cara konvensional seperti terdahulu, tetapi berbasis online, serta bukan lagi word-of-mouth melainkan word-of-internet.

Berbagai konten berupa status update, instastory, minivlog maupun komentar di TripAdvisor turut memberikan dampak terhadap daya dorong keinginan seseorang ataupun preferensi dan keputusan mereka sebelum berwisata. Lebih spesifik di bidang manajemen pariwisata, fenomena ini tentunya peluang besar untuk promosi gratis Bali. Seperti yang diungkapkan oleh Buhalis \& Law (2008) bahwa such widespread use of technology by a growing number of consumers is perhaps more evident in product categories such as tourism. Secara singkat mengungkapkan bahwa perkembangan penggunaan teknologi sangat terlihat nyata untuk pertumbuhan konsumen dan lebih terlihat di pariwisata.

Baik berlibur ataupun membagikan foto sama-sama memberikan pengalaman yang menyenangkan bagi wisatawan milenial. Lambat laun, wisata selfie atau swafoto semakin menjamur. Khususnya di Bali, kini semakin banyak tempat wisata yang mengkhususkan spot untuk berfoto, bahkan sampai dikenal dengan wisata selfie. Destinasi wisata tersebut, tidak dipungkiri menjadi tempat hits kaum milenial dan semakin berlomba untuk mendatanginya.

Pengaruh sosial media ikut mengabil peranan, seperti yang diungkapkan oleh Cavagnaro (2018) bahwa travelling means living an experience of personal development centred on the individual tourist, yang artinya bahwa para milenial mendefinisikan berwisata sebagai hidup dalam pengalaman untuk pengembangan personal yang berpusat pada masing-masing individu, dengan kata lain, fokus berwisata adalah pada pengalaman bukan sebatas menikmati.

Namun, bermunculannya destinasi wisata dengan tujuan sebagai wisata swafoto, tidak dibarengi dengan studi terkini mengenai apa saja yang memotivasi mereka untuk berkunjung serta aktivitas apa saja yang menjadi favorit generasi milenial tersebut. 
Masih sedikitnya penelitian yang membahas mengenai DTW selfie padahal wisata ini sangat potensial untuk dikembangkan, apalagi mengingat generasi milenial memegang peranan penting bagi industri pariwisata saat ini. Seperti yang diungkapkan menurut Boutsiokou (2016) Millennials are a trend-setting generation atau dapat diartikan sebagai generasi milenial menjadi generasi penentu trend terkini.

Oleh karena itu, penelitian ini akan mengkaji mengenai apa saja motivasi wisatawan milenial domestik untuk berkunjung ke DTW swafoto serta preferensi aktivitas wisata mereka selama berkunjung di destinasi tersebut. Sehingga DTW swafoto dapat berkembang, termasuk berpedoman pada pariwisata yang berkelanjutan.

Berdasarkan latar belakang yang telah dipaparkan, maka dapat dirumuskan permasalahan, yakni bagaimana preferensi wisatawan nusantara milenial ketika berkunjung ke DTW Swafoto di Bali?

\section{A. Wisatawan Milenial}

\section{TINJAUAN PUSTAKA}

Kata milenial mulai berkembang pada awal tahun 1980an. Mengenai wisatawan Milenial sendiri, UNWTO (2016) mendefinisikannya sebagai pelancong muda yang lahir di antara tahun 1980 dan 2000. Secara spesifik, UNWTO (2016) menjelaskan karakter wisatawan milenial sebagai kelompok pelancong berpengaruh, yang cenderung memilih hidup seperti masyarakat lokal, memilih menghabiskan uangnya pada bisnis masyarakat lokal, mencari pengalaman baru dan unik yang tidak pernah terjangkau, daerah pedesaan, ataupun wisata niche lokal di daerah tempat tinggal mereka.

Menurut Moreno dkk (2017), istilah milenial juga disamakan dengan Generasi Y dan Echo boomers. $\quad$ Selain itu, dapat dikutip definisi dari Lee \& Kotler (2016) dalam Moreno dkk (2017) bahwa generasi Milenial adalah mereka yang lahir pada tahun 1980-2000.

\section{B. Daya Tarik Wisata Swafoto}

Swafoto awalnya berasal dari bahasa Inggris, yakni selfie. Berdasarkan Kamus Monolingual Oxford Dictionaries, selfie diartikan sebagai photograph that one has taken of oneself, typically one taken with a smartphone or webcam and shared via social media. Diartikan sebagai foto yang diambil sendiri oleh seseorang biasanya dengan telepon genggam atau kamera web dan disebarkan di Sosial Media. Sedangkan, dalam Bahasa Indonesia, selfie kemudian disepadankan dengan kata swafoto. Pada KBBI, definisinya hampir mirip, yakni potret diri yang diambil sendiri dengan menggunakan kamera ponsel atau kamera digital, biasanya untuk diunggah ke media sosial.

\section{Teori Motivasi}

Axelsson (2017:38) menegaskan bahwa motivasi utama memilih DTW swafoto adalah sebagai berikut: travel selfies are motivated by creative efforts at integrating travel experiences with self-expression. Jadi, kegiatan swafoto yang dilakukan wisatawan dimotivasi oleh usaha kreatif dalam mengintegrasi pengalaman berwisata dengan ekspresinya sendiri. 
Berdasarkan berbagai motivasi yang mendorong perjalanan, McIntosh (1977) dalam Yoeti (1886) mengatakan bahwa motivasi dapat dikelompokkan menjadi empat kelompok besar yaitu sebagai berikut:

a. Physical atau physiological motivation (motivasi yang bersifat fisik atau fisiologis)

b. Cultural motivation (motivasi budaya), yaitu keinginan untuk mengetahui budaya, adat, tradisi dan kesenian daerah lain.

c. Social motivation atau interpersonal motivation (motivasi yang bersifat sosial), seperti melakukan hal yang dianggap mendatangkan gengsi (nilai prestise)

d. Fantasy motivation (motivasi karena fantasi), yaitu adanya fantasi bahwa di daerah lain seseorang kan bisa lepas dari rutinitas keseharian yang menjemukan

\section{Teori Atraksi Wisata}

Salah satu teori yang sering digunakan untuk menganalisis atraksi wisata adalah dari Leiper (1990), diungkapkan bahwa terdapat tiga poin penting yang membentuk atraksi wisata sebagai sistem:

"A system comprising of three elements: a tourist or human element, a nucleus or central element and a marker or informative element. A tourist attraction comes into existence when the three elements are connected"

Dapat dijelaskan bahwa sistem tersebut memiliki tiga elemen yakni: elemen manusia yaitu wisatawan itu sendiri; elemen pusat atau inti dan elemen informative atau penanda. Daya tarik wisata akan hidup jika ketiga elemen ini saling melengkapi.

\section{METODE PENELITIAN}

Penelitian ini merupakan penelitian kualitatif secara eksploratif yang dilakukan dengan melakukan pengamatan atau observasi, wawancara mendalam dan dokumentasi. Lokus penelitian adalah pada 5 DTW Swafoto tersebut sebagai berikut: Twin Hill di Kabupaten Gianyar, Big Garden Corner di Kota Denpasar, Tukad Badung di Kota Denpasar, Pantai Merta Sari Sanur dan Wisata Selfie Wanagiri di Kabupaten Buleleng.

Sumber data yang dipergunakan dalam penelitian ini, berasal dari sumber data primer dari informasi yang didapatkan langsung, serta sumber data sekunder yakni berupa literatur, data statistic, teori dan konsep lainnya.

Pengumpulan data dilakukan dengan metode accidental sampling, yaitu teknik atau metode penarikan sampel secara kebetulan yang bersifat emergent sampling yang menunjukkan bahwa sample ditentukan oleh pertimbangan informasi (Sugiyono, 2017:219). Lebih lanjut, berdasarkan Roscoe (1975) dalam Pantiyasa (2013:89) menyebutkan bahwa penelitian eksperimen sederhana menggunakan ukuran sample $10-20$, oleh karena itu pada penelitian ini menyebarkan 10 kuesioner pada 5 DTW, sehingga total terdapat 50 responden.

Teknin analisis data yang digunakan pada penelitian ini adalah mengacu pada Model Miles dan Huberman (1984) dalam Sugiyono (2017:246), dengan tiga tahapan berikut:

a. Reduksi data, yakni mengeliminasi data yang tidak valid 
b. Penyajian data, menyajikan data untuk menjawab rumusan masalah dan melakukan pembahasan dikaitkan dengan teori yang digunakan.

c. Penarikan kesimpulan, membuat kesimpulan sesuai dengan hasil pembahasan

\section{A. Motivasi}

\section{HASIL PENELITIAN DAN PEMBAHASAN}

Motivasi merupakan hal yang paling esensial untuk menarik wisatawan berkunjung, pada penelitian ini dikaji mengenai motivasi internal wisatawan, yang mana motivasi fisik adalah bagaimana keinginan wisatawan untuk meningkatkan kondisi fisiknya, seperti berolahraga dan relaksasi di DTW tersebut. Sementara, motivasi budaya, sosial dan Fantasi, yang berarti keinginan dalam diri wisatawan untuk mempelajari budaya, untuk menyebarkan aktivitasnya saat di DTW ke sosial media, serta fantasi yaitu melepaskan penat dan rutinitas sehari-hari.

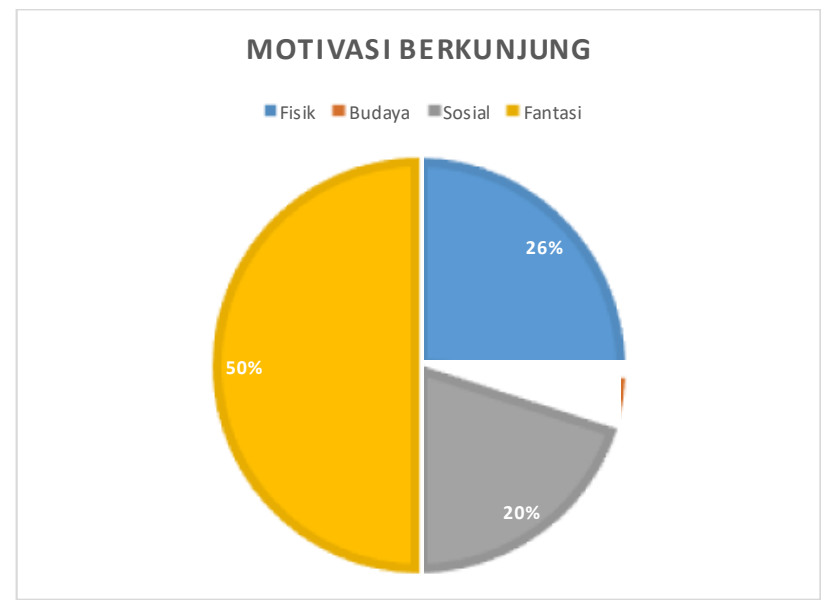

Gambar 1. Motivasi berkunjung

Sumber: Data Penelitian, 2019

Hasil penelitian menunjukkan bahwa motivasi fantasi masih menjadi pilihan dengan prosentase $50 \%$, sedangkan motivasi fisik hanya $26 \%$, sosial $20 \%$, dan budaya hanya 4\%. Dengan demikian, DTW Swafoto memiliki daya tarik tersendiri sebab dapat menjadi selingan bagi wisatawan untuk melepas penat atau refreshing (lihat gambar 1).

B. Preferensi Wisatawan Dari Elemen Manusia, Inti dan Informasi

Lebih lanjut mengenai analisis preferensi wisatawan nusantara milenial dalam berkunjung di DTW Swafoto dapat terlihat bahwa wisatawan nusantara sangat mendukung kinerja pemerintah dan menyambut baik keberhasilan pemangku kebijakan dalam mengembangkan dan memajukan DTW swafoto tersebut, terlihat dari prosentase $94 \%$ wisatawan memilih berkunjung dengan mempertimbangkan keberhasilan pemangku kebijakan dalam mengelola DTW Swafoto (lihat tabel 1).

Disamping itu, wisatawan juga mempertimbangkan preferensi pada jumlah wisatawan pada DTW swafoto dengan prosentase $74 \%$, yakni jika wisatawan 
terlalu membludak maka akan mempengaruhi dan mengurangi kenyamanan dalam berwisata.

Tabel 1 Preferensi Wisatawan Milenial Nusantara di DTW Swafoto

\begin{tabular}{|c|l|r|}
\hline No & \multicolumn{1}{|c|}{ Preferensi } & Prosentase \\
\hline & Manusia & \\
\hline 1 & Preferensi keramahan masyarakat lokal kepada wisatawan & $82 \%$ \\
\hline 2 & Preferensi jumlah wisatawan di DTW tersebut & $74 \%$ \\
\hline 3 & Preferensi keberhasilan citra pemangku kebijakan dalam mengelola DTW tersebut & $94 \%$ \\
\hline & Inti & \\
\hline 4 & Preferensi DTW dalam pemenuhan ekspektasi & $60 \%$ \\
\hline 5 & Preferensi akses menuju lokasi & $80 \%$ \\
\hline 6 & Preferensi ketersediaan dan kelayakan fasilitas umum & $42 \%$ \\
\hline & Informasi & $84 \%$ \\
\hline 7 & Preferensi ketersediaan informasi sebelum memilih berkunjung ke DTW tersebut & $90 \%$ \\
\hline 8 & Preferensi ketersediaan informasi saat berada di lokasi, seperti: arah menuju lokasi & \\
\hline & dan aktivitas yang bisa dilakukan & \\
\hline
\end{tabular}

Sumber: Data Penelitian, 2019

Meskipun demikian, prosentase terkecil terlihat pada ketersediaan dan kelayakan fasilitas umum yakni $42 \%$, meskipun ini belum menjadi preferensi wisatawan, namun sebaiknya mulai ditingkatkan kembali, sebab berdasarkan hasil wawancara, terdapat opini wisatawan yang menyatakan bahwa "kebersihan dan kenyamanan fasilitas perlu dijaga", hal ini juga ditambah dengan kurangnya ketersediaan Toilet dan Wifi atau akses internet.

Hal lainnya yang perlu diperhatikan adalah adanya fasilitas informasi, sebab berdasarkan data yang didapat poin informasi menjadi preferensi wisatawan nusantara dengan prosentase sebesar $84 \%$ dan $90 \%$ untuk sebelum dan saat mengunjungi DTW tersebut.

\section{Aspek yang Perlu Ditingkatkan}

Secara keseluruhan penilaian pengunjung sangat bervariasi, berdasarkan data yang didapat, wisatawan sebagian besar mengatakan DTW swafoto yang dikunjunginya menarik yakni dengan prosentase $44 \%$, kemudian biasa saja dengan prosentase $30 \%$, dan menarik sebesar $26 \%$. Namun, tidak ada wisatawan yang menyatakan Tidak Menarik dan Sangat Tidak menarik (lihat gambar 2. Menariknya, seluruh wisatawan atau 100\% mengungkapkan akan datang kembali, serta $86 \%$ menyatakan akan merekomendasikan DTW swafoto tersebut 


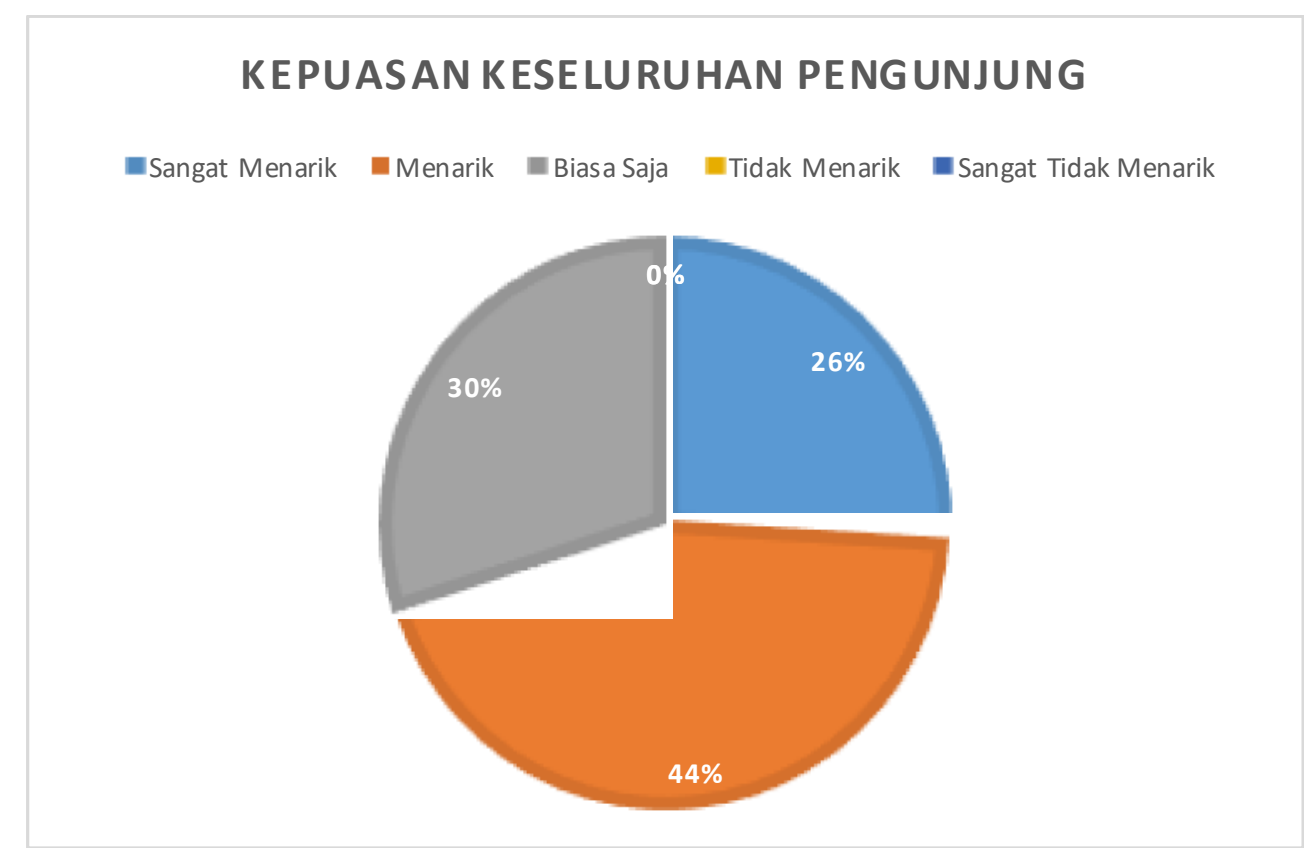

Gambar 2. Kepuasan Keseluruhan Wisatawan Nusantara Milenial Sumber: Data Penelitian, 2019

Meskipun tergolong sukses dan mampu memenuhi kepuasan wisatawan, terdapat beberapa hal nyatanya perlu diperhatikan terkait untuk peningkatan DTW Swafoto. Wisatawan sebagian besar sangat fokus terhadap kebersihan yang ada pada DTW swafoto ini. Beberapa hasil wawancara yang dapat dikutip seperti "tingkatkan kebersihan", "kebersihan dijaga", "perbanyak tempat sampah".

Selain kebersihan, hal yang paling krusial adalah memperbanyak dan meningkatkan ketersediaan fasilitas umum. Dirangkum dari hasil wawancara, fasilitas yang perlu ditambah seperti: akses internet atau wifi, parkir yang memadai atau dilakukan perluasan, toilet, Tourist Information Centre. Disamping itu, beberapa wisatawan juga mengungkapkan perlunya penambahan atraksi wisata baru seperti taman bermain untuk anak, serta spot foto. Wisatawan juga mengungkapkan perlunya penambahan atraksi wisata budaya seperti pegelaran seni, atau event tertentu yang dapat menarik wisatawan untuk datang dan terhibur.

Kemudian, dari segi keamanan, wisatawan menyatakan pentingnya menjaga keamanan, terutama di tempat parkir, sebab sering terjadi beberapa kasus pencurian, sehingga mengganggu kenyamanan wisatawan. Selain tindakan kriminal, keamanan yang perlu ditingkatkan adalah keamanan untuk wisatawan. Hal ini disebabkan pada beberapa spot foto berada di tebing tinggi, posisi yang tinggi ini memang sengaja dipilih untuk mendapatkan pemandangan yang indah, namun sebaiknya perlu dipasang pagar pengaman untuk menjaga keselamatan wisatawan.

\section{KESIMPULAN}

DTW Swafoto yang ada di Bali semakin menjamur. Kehadiran sosial media seperti Instagram dan Facebook turut membantu dalam penyebaran popularitasnya. Berdasarkan hasil penelitian, motivasi wisatawan untuk berkunjung mayoritas 
didorong oleh keinginan untuk keluar atau escape dari rutinitas sehari-hari atau disebut dengan Motivasi Fantasi sebesar 50\%, sedangkan motivasi fisik hanya 26\%, sosial $20 \%$, dan budaya hanya $4 \%$.

Lebih lanjut mengenai analisis preferensinya, wisatawan nusantara sangat mendukung kinerja pemerintah dan menyambut baik keberhasilan pemangku kebijakan dalam mengembangkan dan memajukan DTW swafoto tersebut, terlihat dari prosentase $94 \%$ wisatawan memilih berkunjung dengan mempertimbangkan keberhasilan pemangku kebijakan dalam mengelola DTW Swafoto.

Hasil penelitian juga menunjukkan bahwa terdapat beberapa aktivitas wisata yang perlu dikembangkan untuk mengoptimalkan potensi DTW swafoto, sepert: menggelar event budaya secara reguler, menambah taman bermain untuk anak-anak, menambah spot untuk berswafoto, serta merenovasi spot swafoto yang sudah kurang layak. Disamping itu, wisatawan juga memandang perlunya menjaga kebersihan dan penambahan atraksi wisata baru.

\section{DAFTAR PUSTAKA}

Axelsson, Patrina Jessica. 2017. Travel Selfie: A commodification of the tourist experience and culture? (Undergraduate Thesis). Malmo University

Boutsioukou, Konstantina. 2018. Global Data: Key Trends in Culinary Tourism. Diunduh dari: https://sector.tov.be/wpcontent/uploads/2018/11/GlobalData_Keytrends inculinarytourism 130918.pdf, pada tanggal 5 April 2019

Buhalis, D., \& Law, R. 2008. "Progress in information technology and tourism management: 20 years on and 10 years after the Internet - the state of eTourism research". Tourism Management, 29(4), 609 - 623.

Cavagnaro, et al. 2018. “Understanding Millennials' Tourism Experience: Values and Meaning to Travel As a Key for Identifying Target Clusters for Youth (Sustainable) Tourism", Journal of Tourism Futures, 4(1), 31-42. Diunduh dari: https://www.emeraldinsight.com/doi/pdfplus/10.1108/JTF-12-2017$\underline{0058}$, pada tanggal 5 April 2019

Dewi, MC. 2016. "Petualangan Seru di Big Garden Corner, Keindaha 600 Patung dan Hamparan Sawah", Tribun Bali, Diakses dari: https://bali.tribunnews.com/2016/ 11/11/petualangan-seru-di-big-gardencorner-keindahan-600-patung-dan-hamparan-sawah?page=all, pada tanggal 7 Agustus 2019

Furlow, N. E. 2012. Find us on Facebook: How Cause Marketing has Embraced Social Media. Journal of Marketing Development \& Competitiveness, 5(6), 61-64. Retrieved from http://ezproxy.lib.swin.edu.au/login?url=http://search.ebscohost.com/login. aspx? direct $=$ true $\& d b=$ bth $\& A N=71825618 \&$ site $=$ ehost-live $\&$ scope $=$ site

Leiper, N., 1990. Tourist attraction systems. Annals of Tourism Research, 17(2): 367-384

Moreno, dkk. 2017. "The Characterization of the Millennials and Their Buying Behavior", International Journal of Marketing Studies, Vol. 9, No. 5, pp. 135-144

Pantiyasa, IW. 2013. Metodologi Penelitian. Denpasar: STPBI 
Parhusip, NE \& INS Arida. 2018. "Wisatawan Milenial di Bali (Karakteristik, Motivasi dan Makna Berwisata)", Jurnal Destinasi Pariwisata, Vol. 6, No.2, pp. 299-303. p-ISSN: 2338-8811, e-ISSN: 2548-8937

Petter, Olivia. 2018. "Millennials Set to be Outnumbered By Gen Z Within A Year" Diakses dari: https://www.independent.co.uk/life-style/millennials-gen-Zoutnumbered-2019-global-population-demographic-bloomberga8502251.html, pada tanggal 7 Agustus 2019

Phillips, Kevin E. 2019. Managing Millenials: The Ultimate Handbook for Productivity, Profitability and Professionalism. New York: Routledge

Sugiyono. 2018. Metode Penelitian Kombinasi. Bandung: Alfabeta

Veiga, Célia, dkk. 2017. "Are millennials transforming global tourism? Challenges for destinations and companies", Worldwide Hospitality and Tourism Themes, Vol. 9 Issue: 6, pp.603-616. Diakses dari: https://doi.org/10.1108/ WHATT-09-2017-0047, pada tanggal 20 April 2019

World Tourism Organization. 2016. Affiliate Members Global Reports, Volume thriteen - The Power of Youth Travel. Madrid: UNWTO

Wiwin, I Wayan. 2019. "Wisata Minat Khusus sebagai Alternatif Pengembangan Pariwisata di Kabupaten Bangli", diakses dari: ejournal.ihdn.ac.id/index.php/PB/article/ download/840/696, pada tanggal 9 Agustus 2019 